\title{
Time evolution of dislocation formation in ion implanted silicon
}

\author{
J. R. Liefting \\ FOM Institute for Atomic and Molecular Physics, Kruislaan 407, 1098 SJ Amsterdam (Netherlands) \\ and Twente University, MESA Research Institute, PO Box 217, 7500 AE Enschede (Netherlands) \\ J.S. Custer and F. W. Saris \\ FOM Institute for Atomic and Molecular Physics, Kruislaan 407, 1098 SJ Amsterdam (Netherlands)
}

(Received September 7, 1993)

\begin{abstract}
Annealing of crystal damage from ion implantation may result in dislocation formation. Here we study the nucleation, growth, and annihilation of such dislocations during rapid thermal anneals of $\mathrm{Si}, \mathrm{Ge}$, As, and In implanted $\mathrm{Si}$. The dislocation formation process is observed for single or multiple damage profiles, as well as in amorphous-crystal transition regions. Dislocations initially nucleate in all these cases, even if they eventually annihilate during further annealing. It is also shown that for $\mathrm{C}$ implants in Si not only do dislocations not remain after annealing, but they do not even nucleate.
\end{abstract}

\section{Introduction}

Ion implantation technology is widely used in the semiconductor industry for introducing dopants into silicon [1]. The major drawback is that secondary defects, extrinsic interstitial dislocations, may form during the thermal treatment required to anneal out the implant damage and activate the dopants [2-6]. These secondary defects can be detrimental to device performance. Therefore, much effort has been put into determining when or how these dislocations form $[4$, 6-9]. In particular, it has been demonstrated for room temperature (RT) implants that dislocations are present after annealing only if more than a critical number of atoms have been displaced by the implant [6]. That is, for a given ion and implant energy, there is a threshold dose above which dislocations form during a standard anneal (e.g. $15 \mathrm{~min}$ at $900^{\circ} \mathrm{C}$ ).

Ion implantation generates crystal damage in the $\mathrm{Si}$, which will in general consist of simple point defects, defect clusters, and amorphous regions. During annealing, the amorphous regions recrystallize, while the point defects interact to either annihilate in interstitial-vacancy pairs, or make larger point defect clusters, which may eventually result in dislocation formation. Although dislocation formation appears to result from nucleation and growth of stable dislocations in a sea of point defects, it is still not clear which stages of dislocation formation require the critical amount of implant damage. Even so, there has been much work to determine if, for example, different implant or anneal temperatures can be used to minimize or avoid dislocation formation [10-14].

It would be desirable to know what processes affect formation and why there is a critical damage level needed. Towards that end, we present here a study of the time evolution of dislocations in samples annealed in a rapid thermal annealer (RTA). Four different examples of dislocation formation are investigated. First, we show that dislocations rapidly nucleate in samples implanted with doses either above or below the critical damage level. However, for sub-threshold implants the dislocations never reach a stable size and eventually anneal out. Second, damage profiles at different depths can interact, resulting in nearly complete suppression of dislocation formation in the region with the lowest damage [6]. Here we show that dislocations nucleate faster in a narrow, high density defect region. Once these dislocations form, they efficiently getter the damage from the other implant region. Third, amorphizing implants performed at room temperature result in end-of-range (EOR) dislocation loops forming at the original position of the amorphous-crystal interface, while a liquid nitrogen temperature implant does not form dislocations $[10,15]$. We show here that dislocations nucleate in both cases, but they rapidly disappear in the case of the $\mathrm{LN}_{2}$ implants. Finally, we investigate the behavior of $\mathrm{C}$ implanted samples. Carbon implants do not lead to dislocation formation $[5,16]$ and can even suppress dislocation formation that would other- 
wise occur from a co-implanted species [14]. In the C-implanted samples we do not observe dislocation formation for any annealing stage.

\section{Experimental details}

Implants of $\mathrm{C}, \mathrm{Si}, \mathrm{Ge}, \mathrm{As}$, and In at energies between $75 \mathrm{keV}$ and $1 \mathrm{MeV}$ were carried out in $5-15 \Omega \mathrm{cm} p$ type (100) Si. The number of displaced atoms in the asimplanted samples was determined with Rutherford backscattering spectrometry (RBS) in the channeling geometry using $2 \mathrm{MeV} \mathrm{He}$. The implanted samples were annealed at $900^{\circ} \mathrm{C}$ in an RTA in an Ar ambient for times from 1 to $300 \mathrm{~s}$. The temperature ramp-up in the RTA was $10 \mathrm{~s}$, and all anneal times started from when a temperature of $900^{\circ} \mathrm{C}$ was reached. Anneals for $15 \mathrm{~min}$ at $900^{\circ} \mathrm{C}$ were performed in a vacuum furnace (base pressure $10^{-7}$ Torr). Cross-section transmission electron microscopy (XTEM) was performed on samples made using standard polishing and ion milling procedures.

\section{Results and discussion}

\subsection{Critical damage level}

Figure 1 shows RBS channeling spectra for $\mathrm{Si}$ implanted with $1 \mathrm{MeV}$ In to doses of $1.5,2.0$ and $4.0 \times 10^{13} \mathrm{~cm}^{-2}$. The damage profiles peak at a depth of $400 \mathrm{~nm}$ and have a full-width at half-maximum (FWHM) of $300 \mathrm{~nm}$. The number of displaced $\mathrm{Si}$ atoms for each implant, as calculated using the method of Chu et al. [17] are 1.5, 1.9 and $4.5 \times 10^{17} \mathrm{~cm}^{-2}$,

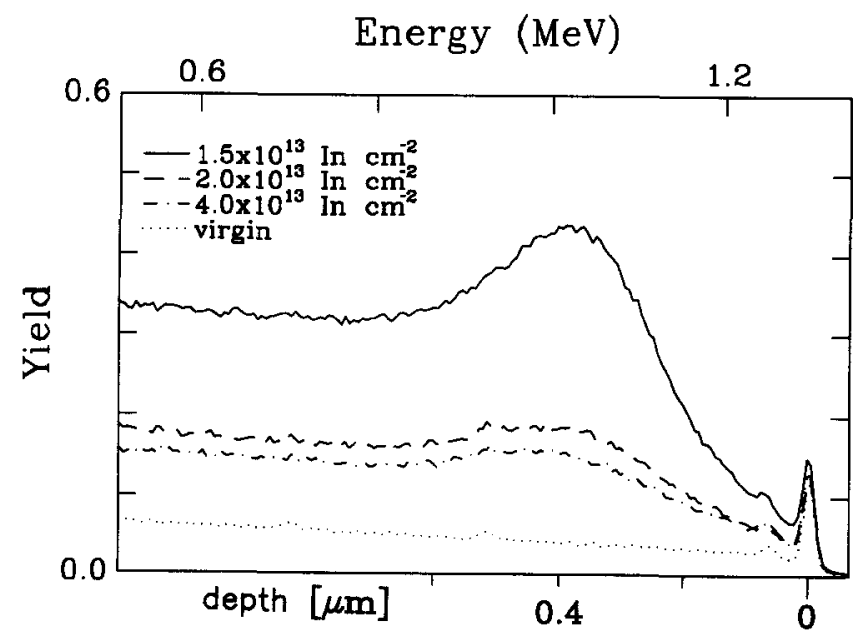

Fig. 1. RBS channeling spectra for Si implanted with $1.5,2$, or $4 \times 10^{13} \mathrm{~cm}^{-2} 1 \mathrm{MeV}$ In. The damage profiles peak at a depth of $400 \mathrm{~nm}$ and have FWHM of $300 \mathrm{~nm}$. A spectrum for virgin $\mathrm{Si}$ is shown for comparison. respectively. From previous work it is known that the critical amount of damage is reached for the $2.0 \times 10^{13} \mathrm{~cm}^{-2}$ implant [6].

Figure 2 shows XTEM images of these samples as a function of the anneal time at $900^{\circ} \mathrm{C}$. After only $5 \mathrm{~s}$, a high density of short dislocation rods, as well as a few loops, are observed near the projected range (approximately $400 \mathrm{~nm}$ ) of all the In implants. The higher the implanted dose, the higher the number of dislocations. After $20 \mathrm{~s}$ of annealing, only a few dislocation loops remain in the lowest dose $\left(1.5 \times 10^{13} \mathrm{In} \mathrm{cm}^{-2}\right)$ sample, while the higher dose samples have more loops, as well as some remaining rods. After $1 \mathrm{~min}$, the low dose sample contains only one dislocation loop, and no dislocations can be found for longer anneal times. In contrast, a stable dislocation population remains in the higher dose samples.

Dislocations nucleated and grew in all three samples, but the dislocations annealed out again in the lowest dose sample. Clearly, dislocation nucleation is not the limiting step in dislocation formation, since a large number of dislocations are observed to rapidly nucleate in all samples. However, during continued annealing, the dislocations in the low dose In sample disappear. It is known that at a given anneal temperature only dislocations larger than a critical size are stable, and that smaller ones will anneal out [18]. This suggests that the observed criterion of needing a critical amount of displaced $\mathrm{Si}$ atoms arises from the requirement of nucleating and then growing dislocations that are large enough to be stable at the anneal temperature. If there are too few defects available, then no dislocation will become large enough to be stable before the highly non-equilibrium population of point defects anneals out.

\subsection{Interaction between damage profiles}

Previous work has shown that two different implant damage profiles can interact during annealing, altering the final dislocation density and position [6]. However, it is not known if the interaction takes place before, during, or after dislocation formation. Figure 3 shows RBS channeling spectra from Si implanted with either $4 \times 10^{14} \mathrm{~cm}^{-2} 150 \mathrm{keV} \mathrm{Si}, 6 \times 10^{13} \mathrm{~cm}^{-2} 1 \mathrm{MeV} \mathrm{As}$, or both $4 \times 10^{14} \mathrm{~cm}^{-2} 150 \mathrm{keV}$ Si and $6 \times 10^{13} \mathrm{~cm}^{-2}$ $1 \mathrm{MeV}$ As. The Si implant damage profile peaks at a depth of $170 \mathrm{~nm}$, and contains $2 \times 10^{17} \mathrm{~cm}^{-2}$ displaced Si atoms, more than four times the critical number required for dislocation formation for Si implants [6]. The As damage profile peaks at $570 \mathrm{~nm}$, and contains $3 \times 10^{17} \mathrm{~cm}^{-2}$ displaced atoms, about twice the critical number for dislocation formation from As implants. The concentration of displaced atoms in the surface (Si-implanted region) is some four times higher than in the deeper As-implanted region. 

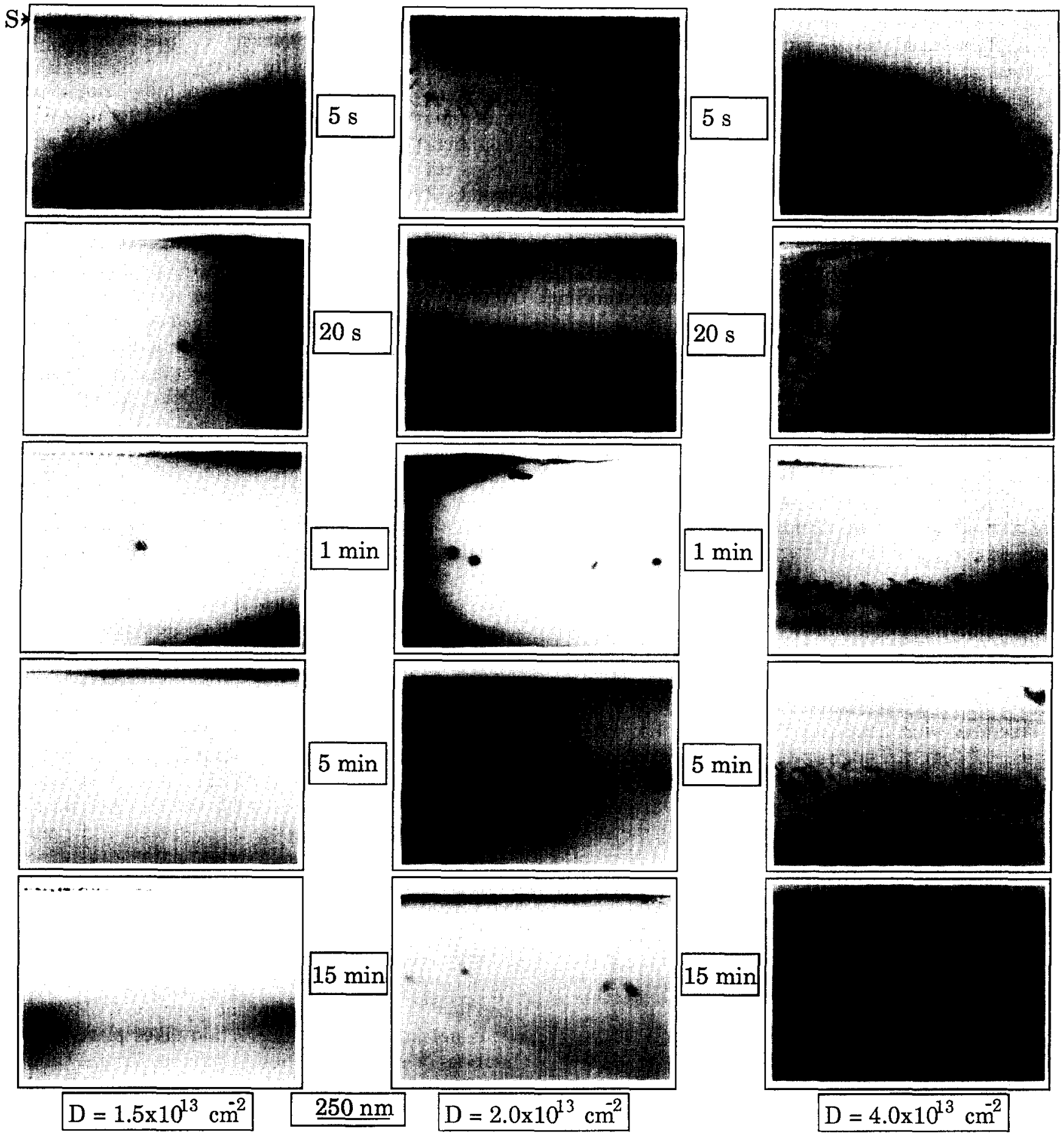

Fig. 2. Cross-sectional TEM images after different anneal times at $900^{\circ} \mathrm{C}$ for samples implanted with $1.5,2$, or $4 \times 10^{13} \mathrm{~cm}^{-2} 1 \mathrm{MeV}$ In. In the lowest dose sample, dislocations are observed to nucleate and then disappear, while at the higher doses dislocations remain after annealing.

Figure 4 shows XTEM images after RTA anneals for times between $1 \mathrm{~s}$ and $5 \mathrm{~min}$ for the $\mathrm{Si}$, As, and $\mathrm{Si}+$ As implants. After only $1 \mathrm{~s}$ at $900^{\circ} \mathrm{C}$, the sample implanted with $4 \times 10^{14} \mathrm{~cm}^{-2} 150 \mathrm{keV}$ Si already contains dislocations. These dislocations steadily evolve into the high density of dislocation loops that remain after $5 \mathrm{~min}$ of annealing. In contrast, the sample implanted with $6 \times 10^{13} \mathrm{~cm}^{-2} 1 \mathrm{MeV}$ As contains no visible dislocations after $1 \mathrm{~s}$; short dislocation rods are observed only after $5 \mathrm{~s}$ of annealing. These dislocation rods evolve towards dislocation loops, and do not achieve a stable configuration until after more than 


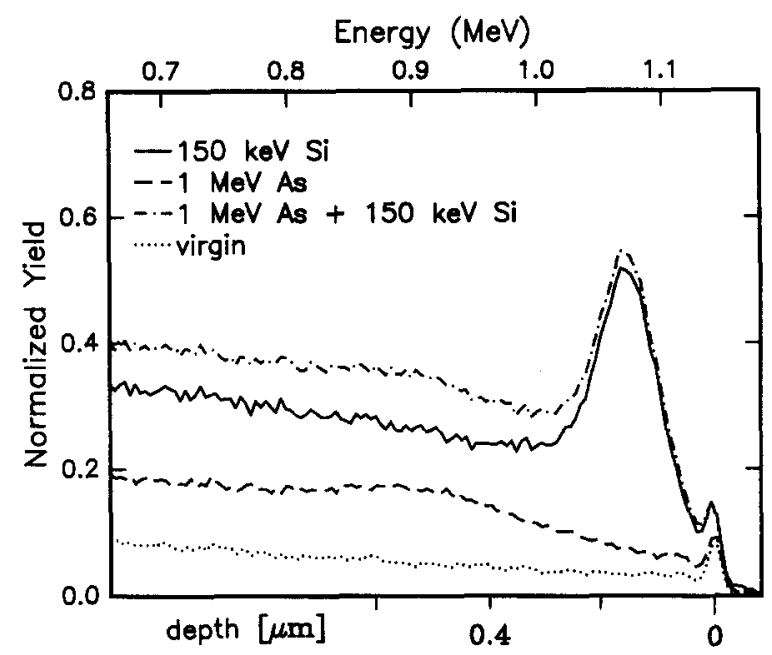

Fig. 3. RBS channeling spectra for samples implanted with either $4 \times 10^{14} \mathrm{~cm}^{-2} 150 \mathrm{keV} \mathrm{Si}, 6 \times 10^{13} \mathrm{~cm}^{-2} 1 \mathrm{MeV} \mathrm{As}$, or both $4 \times 10^{14} \mathrm{~cm}^{-2} 150 \mathrm{keV} \mathrm{Si}$ and $6 \times 10^{13} \mathrm{~cm}^{-2} 1 \mathrm{MeV}$ As. The shallower Si damage profile is centered at a depth of $170 \mathrm{~nm}$, while the As damage profile is centered near a depth of $570 \mathrm{~nm}$.

$1 \mathrm{~min}$ of annealing. This behavior is similar to the intermediate In dose shown in Fig. 2. For the combined $\mathrm{Si}+$ As implant, $1 \mathrm{~s}$ of annealing is sufficient for short dislocation rods to form within the Si damage profile, as is the case for the Si-only implant. After $5 \mathrm{~s}$, the dislocation rods in the Si damage region are evolving towards dislocation loops, and a low density of dislocation rods are observed in the As damaged region. The density of dislocations there is, however, much lower than in the case of the As-only implant. After $20 \mathrm{~s}$, a high concentration of dislocation loops is present near the surface, and only a very low density of dislocation rods can be observed in the As damaged area; again the concentration of dislocations in this region is much lower than for the As-only sample. The sample annealed for $5 \mathrm{~min}$ exhibits nearly no dislocations in the As damaged region. The faster nucleation of dislocations in the near-surface region has helped deplete the deeper region of the point defects needed for dislocation formation.

\subsection{End-of-range loops}

It is clear that narrow damage profiles nucleate dislocations faster than wider damage profiles. One way to obtain a very narrow damage profile in crystal $\mathrm{Si}$ is to perform an amorphizing implant. In addition to a surface amorphous layer, this also produces an amorphous-crystal transition region, with a high density of damage in the crystal. The nature of this transition region can be changed by, for example, amorphizing with different ion species, where differences in ion range straggling may affect the width of the transition region. Here we will use one ion, Ge, and implant at either room or liquid nitrogen temperature.

Implants of $75 \mathrm{keV}$ Ge were performed at RT $\left(5 \times 10^{14} \mathrm{~cm}^{-2}\right)$ and liquid nitrogen (LN) temperature $\left(4 \times 10^{14} \mathrm{~cm}^{-2}\right)$. These implants result in a continuous surface amorphous layer with a thickness of $100 \mathrm{~nm}$. From RBS channeling measurements after low temperature anneals, the thickness of the amorphouscrystal transition region was estimated to be about $10 \mathrm{~nm}$ for both samples. Figure 5 shows cross-sectional TEM images of these samples after annealing at $900^{\circ} \mathrm{C}$ for various times. After $1 \mathrm{~s}$, the RT-implanted sample contains a high density of dislocations (loops and rods). These quickly evolve into EOR loops, reaching a stable configuration with $5 \mathrm{~s}$. In the sample implanted at LN temperature, dislocations are also present after $1 \mathrm{~s}$ of annealing, although the density is much lower than in the RT case. After $5 \mathrm{~s}$ of annealing, these dislocations have annealed out. This suggests that, as for the low dose In implant of Fig. 2, the LN temperature implant does not contain sufficient crystal damage to form stable dislocations.

\subsection{Carbon implants}

It is known that $C$ implants do not lead to dislocation formation during annealing, and can even suppress the expected dislocation formation from co-implanted ions [5-14]. However, it is not known why dislocations are suppressed by carbon. Here we have implanted $5 \times 10^{14} \mathrm{~cm}^{-2} 800 \mathrm{keV} \mathrm{C}$ into Si. The crystal damage from this implant is centered on a depth of $1.1 \mu \mathrm{m}$, and contains $2 \times 10^{17}$ displaced $\mathrm{Si}$ atoms per square centimeter. This damage level is more than 10 times higher than that required to form stable dislocations for a B implant, an ion with nearly the same mass $[6,14]$. Figure 6 shows cross-sectional TEM images of the $\mathrm{C}$-implanted sample after various anneal times at $900^{\circ} \mathrm{C}$. It is remarkable that dislocations are not observed for any anneal time. This is in sharp contrast with the examples above, where dislocations always nucleated, even if they annealed out at a later stage. It can be concluded that $\mathrm{C}$ affects the dislocation nucleation process and does not, for example, increase the critical dislocation size.

\section{Conclusions}

The time evolution of dislocation formation during RTA anneals of ion implant damage has been studied. The criterion for dislocation formation [6] exceeding a certain number of displaced atoms per unit area, appears to be the result of the need to nucleate and grow dislocations of a critical size. Different damage 

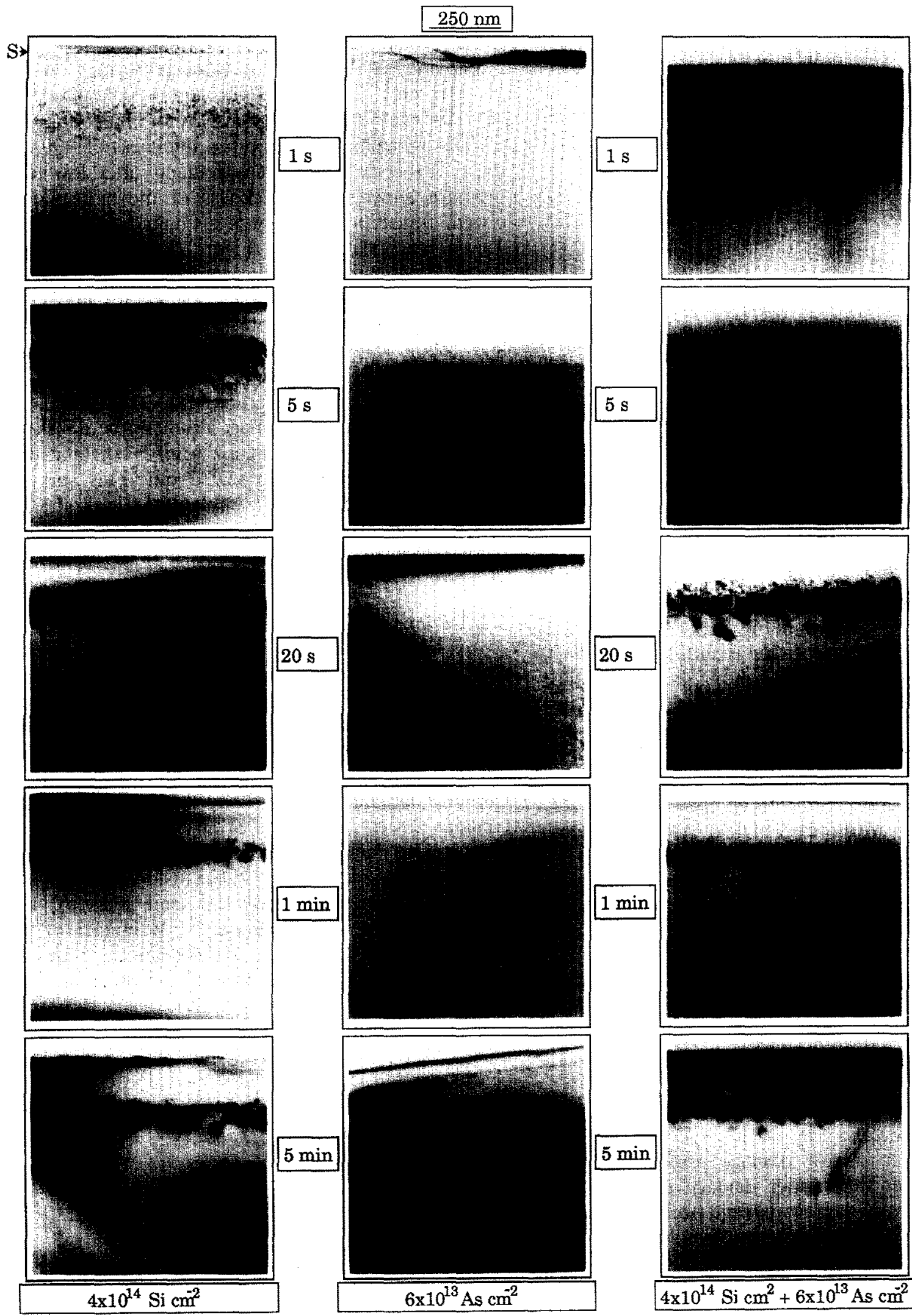

Fig. 4. Cross-sectional TEM images after different anneal times at $900^{\circ} \mathrm{C}$ for samples implanted with either $4 \times 10^{14} \mathrm{~cm}^{2} 150 \mathrm{keV} \mathrm{Si}$, $6 \times 10^{13} \mathrm{~cm}^{2} 1 \mathrm{MeV}$ As, or both $4 \times 10^{14} \mathrm{~cm}^{2} 150 \mathrm{keV} \mathrm{Si}$ and $6 \times 10^{13} \mathrm{~cm}^{2} 1 \mathrm{MeV}$ As. Dislocations appear sooner in the Si damage region than in the As damage region. In the case of the combined Si and As implant, this faster nucleation results in the near-surface dislocations suppressing the formation of dislocations in the deeper damage region. 


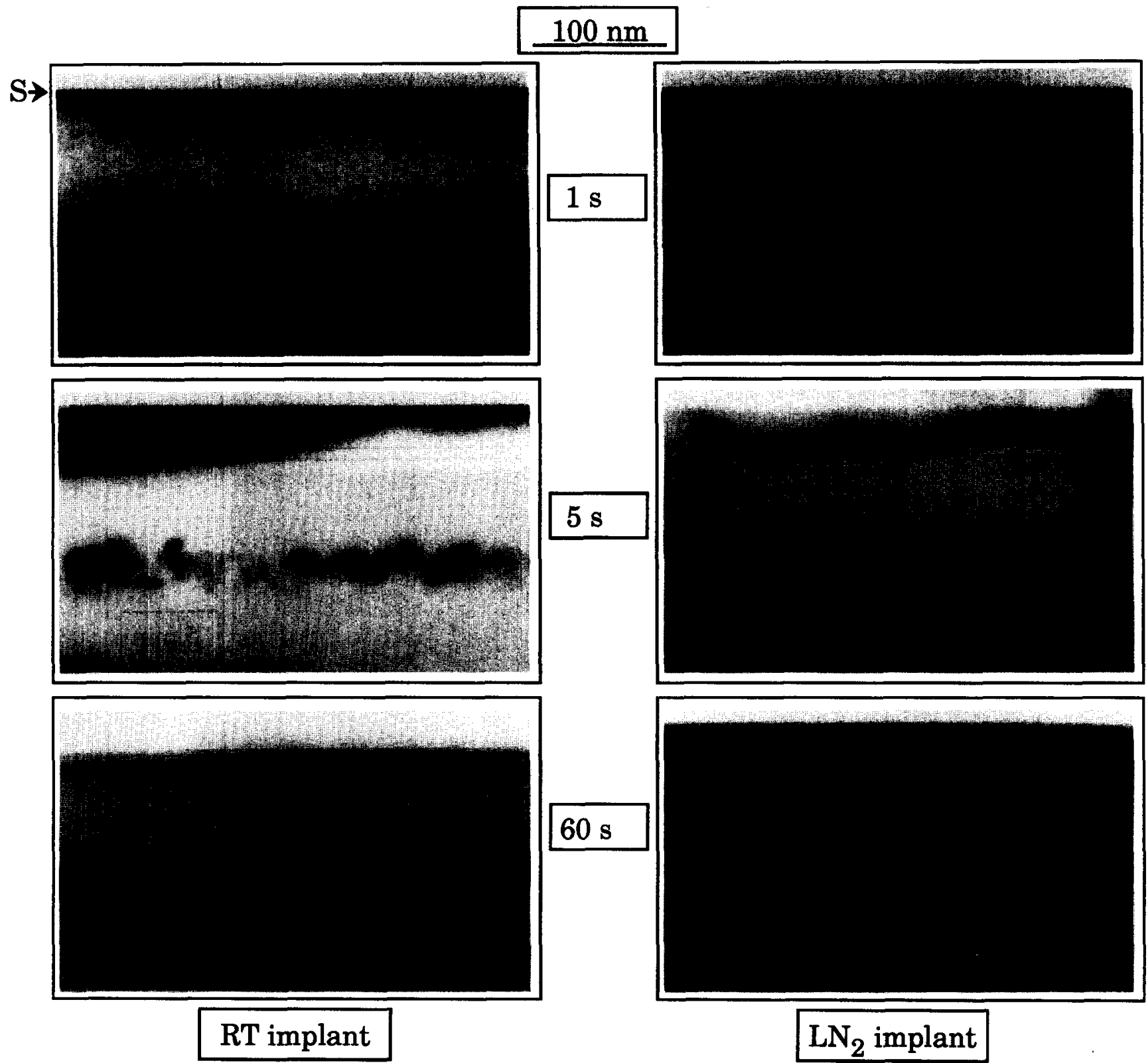

Fig. 5. Cross-sectional TEM images after different anneal times at $900{ }^{\circ} \mathrm{C}$ for Si samples amorphized by Ge implants at either room or liquid nitrogen temperature. For the RT implant, dislocations quickly nucleate and evolve to become EOR loops. For the cold implant, a lower density of dislocations appears, and then rapidly anneals out.

profiles interact during the process of nucleation and growth of dislocations. The suppression of EOR dislocation loops by low temperature implants appears to be the result of not having enough crystal damage, because the appearance and subsequent annealing out of dislocations is similar to the case of low dose room temperature implants. Finally, annealing of damage from $\mathrm{C}$ implants does not result in dislocation nucleation.

\section{Acknowledgments}

We thank J. Klappe for supplying us with the Asimplanted Si wafers. This work is part of the research program of the Foundation for Fundamental Research on Matter (FOM) and was made possible by financial support from the Dutch Organization for the Advancement of Pure Research (NWO) and Varian Ion Implant Systems. 

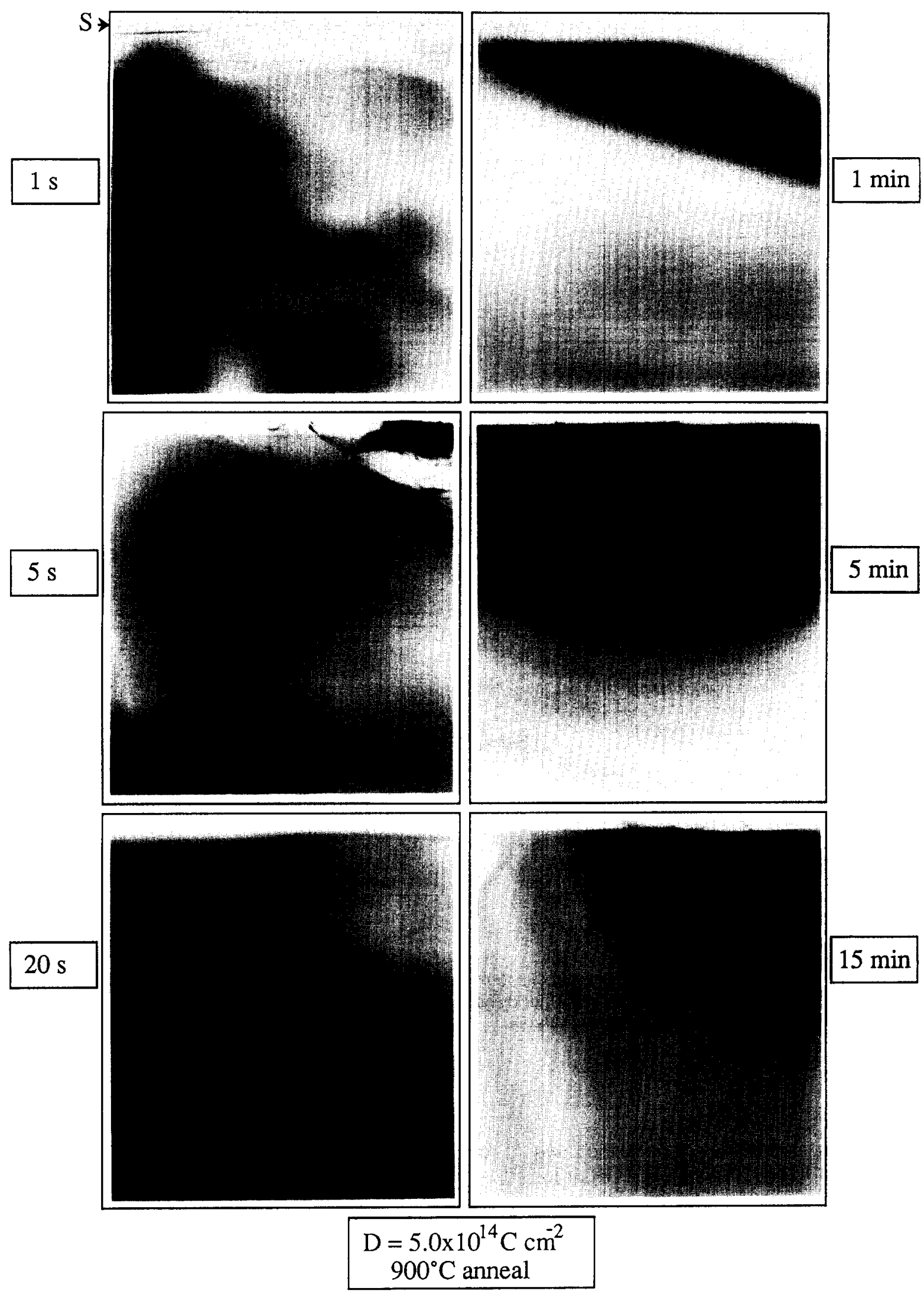

Fig. 6. Cross-sectional TEM images after different anneal times at $900^{\circ} \mathrm{C}$ for Si implanted with $5 \times 10^{14} \mathrm{~cm}^{-2} 800 \mathrm{keV} \mathrm{C}$. Dislocations are not observed after any anneal time. 


\section{References}

1 S. Namba (ed.), Ion Implantation in Semiconductors, Plenum Press, New York, 1975.

2 R. S. Nelson, in Proc. Int. Conf. on Radiation Damage and Defects in Semiconductors, US Air Force, 1973.

3 S. Mader, H. Ryssel and H. Glawischnig (eds.), in Ion Implantation Techniques, Springer, Berlin, 1982.

4 K. S. Jones, S. Prussin and E. R. Weber, Appl. Phys. A, 45 (1988) 1.

5 M. Tamura, Mater. Sci. Rep., 6 (1991) 141.

6 R. J. Schreutelkamp, J. S. Custer, J. R. Liefting, W. X. Lu and F. W. Saris, Mater. Sci. Rep., 6 (1991) 275.

7 F. F. Morehead and B. L. Crowder, Radiat. Eff., 6 (1970) 27.

8 T. Y.Tan, Mater. Res. Soc. Symp. Proc., 2 (1981) 163.

9 K. Seshan and J. Washburn, Radiat. Eff., 37 (1978) 147.

10 M. Servidori and I. Vecchi, Solid-State Electron., 24 (1981) 329.
11 W. X. Lu, Y. H. Qian, R. H. Tian, Z. L. Wang, R. J. Schreutelkamp, J. R. Liefting and F. W. Saris, Appl. Phys. Lett., 55 (1989) 1838.

12 R. J. Schreutelkamp, J. R. Liefting, J. S. Custer and F. W. Saris, Appl. Phys. Lett., 58 (1991) 2827.

13 J. R. Liefting, V. Raineri, J. S. Custer, R. J. Schreutelkamp and F. W. Saris, Mater. Res. Soc. Symp. Proc., 235 (1992) 173.

14 J. R. Liefting, J. S. Custer, R. J. Schreutelkamp and F. W. Saris, Mater. Res. Soc. Symp. Proc., 235 (1992) 179.

15 J. R. Liefting, J. S. Custer, R. J. Schreutelkamp and F. W. Saris, Mater. Sci. Eng., B15 (1992) 173.

16 H. Wong, N. W. Cheung, P. K. Chu, J. Liu and J. W. Mayer, Appl. Phys. Lett., 52 (1988) 1023.

17 W. K. Chu, J. W. Mayer and M.-A. Nicolet, Backscattering Spectrometry, Academic Press, New York, 1978.

18 W.-K. Wu and J. Washburn, J. Appl. Phys., 48 (1977) 3747. 